\title{
Discussion-provocation as a method of improving the educational process
}

\author{
Olga Nikolenko ${ }^{1}$, Larisa Babakova ${ }^{1}$, and Boris Morenko ${ }^{1, *}$ \\ ${ }^{1}$ Don State Technical University, Gagarin Square, 1. Rostov-on-Don, 344003, Russia
}

\begin{abstract}
The article describes the methodology of conducting training sessions in the discussion-provocation form as one of the methods of improving speech and thinking skills while teaching Russian as a foreign language in the classroom at an advanced training level and proves its effectiveness in mastering communication skills. It is shown that conducting training sessions in the discussion-provocation form helps to develop speech production skills among foreign students, to unleash creativity and logical thinking, making them to pass and process the information of the suggested basic text through "I-position" the prism. It enriches foreign students with elements of personally marked evaluation, thereby realizing the cognitive, communicative and educational tasks of the learning process. The advantages of authentic texts as an initial base for the speech skills development are described, as far as they reflect the real needs and emotional students' mood through their approach to the surrounding reality and the interests of a particular individual, orient his thoughts to a given attitude. Discussion-provocation, being a non-standard form of classes helps to form an abstract and scientific world view among foreign students.
\end{abstract}

\section{Introduction}

Modern education increasingly "tighten up" the requirements for the process university education process (including teaching Russian as a foreign language) and for its methodological tactics. Taking into account this situation, methodologists of all scientific branches set the goal of searching for new approaches to the knowledge presentation aimed at the formation of a communicative personality capable of self-expression both in their native language and in the foreign language being mastered. In this regard, the works by L. Stoll are relevant, who believed that in the conditions of the educational process intensification, the teacher-mentor must expand his methodological and methodical scopes, having offered a new look at the hierarchical cognition layers [1]. This "view" is possessed by modern scientists-practitioners who propose methods based on provocative tactics. For example, H. Clark, classifying discussion-provocation to the special interactive methods, believes that it helps students to self-determine, develop a personally marked attitude to educational material, and motivate them to learn it more deeply [2]. J. Gregersen-Hermans proves that this method develops the ability to listen to the opponent's opinion in a friendly

\footnotetext{
*Corresponding author: bmorenko@mail.ru
} 
and tolerant way [3], which is certainly very important in a multicultural audience. T.S. Rodgers, M. Baker, C. Borghetti, T. Harden and their scientific successors and followers put forward the idea that discussion-provocation enlivens interpersonal and intellectual processes in students, as it teaches them to formulate arguments to their opinion, promotes self - control, and serves as a factor in activating educational and cognitive activities $[4,5$, $6,7]$. Researches of the above scientists allow the authors of this article to come to the conclusion that the debate-provocation is an educational tool that guides the learner in the direction of communicative "emancipation" and to submit for methodological consideration the idea that, in addition to all that has been said, this method promotes the formation of his recipient speech I-incarnation in the context of national culture, taking into account specific structural and semantic properties of language.

\section{Problem Statement}

The relevance of the proposed work is due to the need to find such a method of speechthinking teaching activities in the framework of the Russian language as a foreign language, which will meet the requirements of the State standard in this relevant field, and not suppress the language personality in the student. The expediency of developing the speech of foreigners on the basis of artistic authentic texts is justified by the fact that they better contribute to the activation of speech-thinking activities and the formation of a person who is successful in the communicative plan.

The methodology used by the authors is implemented through the model of language teaching as a complex self-developing system, which creates for recipients an understanding of the holistic linguistic picture of the world and the skills and abilities to independently produce a text independently, taking into account the requirements of the modern educational system.

\section{Main Part}

In the modern methodological literature, a discussion-provocation is understood as a method of involving a student in a dispute, in which his initiator (in our case, a teacher) deliberately exacerbates the communication situation, using the personal experience of its participants, "indicates contradictions between their arguments, making them to doubt their own opinion and look for new arguments" [8], thereby artificially stimulating the creation of a situation in which a speech attack grows, provoking all participants to participate in lively debates. Discussion-provocation on problematic topics as a methodical technique in the classroom in the Russian language as a foreign language, it is most appropriate to implement it at an advanced stage of learning, when students have sufficiently mastered the skills of speaking the language they are studying. In this case, we believe, the main goals of this type of dispute will be realized, which include the creation of a real incentive to carry out communication within the framework of reasoned evidence, the formation of logical thinking, and revealing the creative potential of the addressee of training. In order to get the whole audience involved in the discussion-provocation, it is necessary to choose as the language material those materials that are authentic for students and are focused on the socio-cultural and professional sphere of the communicant, since they reflect to a greater extent life realities that satisfy the social needs of young people and correspond to their psychological and age-related needs. These can be newspaper or magazine articles, information from Internet sites, excerpts from television programs, feature films, that help foreigners get to know Russia better, get to know its people, life and culture. Being the most massive means of information and propaganda in modern society, such sources, 
through their compositional narrative theme, forming already formed in the title of the text, not only introduce readers (listeners) to the course of current events taking place in the world, but also, creating information veils through various semantic nominations and syntactic constructions, are forced to consider their content plan through the prism of selfposition, which allows you to solve cognitive, communicative and educational tasks of education. This reveals the specificity of the units functioning in the authentic text, the semantics of which is enriched with elements of social evaluation.

In order the act of communication passes successfully within the framework of a discussion-provocation, the student must understand not only the idea of the text (presented orally or in writing), but also overcome the discrepancies between his awareness and the information content of the material, which arise both due to insufficient linguistic training, and non-possession of background knowledge on the topic under discussion, which, refracted under the author's self-vision, creates a certain motivation for correcting one's perception [9]. We believe that words with a background meaning must necessarily be included in the pre-discussion commentary, as it is the background interpretation of the lexeme, being an important component of the author's idiostyle, is able completely remove the semantic veil from the context through the ratios of syntactic meaning with the means of its expression [10]. Besides, this type of vocabulary determines the repeatability and uniformity of its content, which, in turn, makes it possible to compile lists of nonequivalent and background words by topic and to highlight keywords that accumulate the knowledge of native speakers who carry out the very act of communication within the framework of the described strategy.

Educational discussion-provocation requires from the teacher a lot of experience, skill, the most thorough preparation in organizing and conducting this kind of classroom work [11]. He must put forward problematic theses in order to create an appropriate atmosphere, and skillfully, without pressure, lead the entire course of the provocative discussion, directing it in the right direction. If he succeeds, then the result of the work done will be not only the rapid assimilation of the presented vocabulary and speech cliches, the ability easily to enter into communication, but also the removal of cultural and communicative barriers, which is important for improving the methods of teaching coherent speech in the lessons of Russian as a foreign language.

The methodology for conducting such classes is diverse. We will focus on one of the possible ways of organizing them. We believe that work on this type of activity should include two stages: preparatory and main. The preparatory one provides the introduction and consolidation of speech structures and the most commonly used phrases in the provocative discussion (for example, units of speech etiquette that formalize the speaker's appeal to other participants in the discussion-provocation; speech formulas expressing agreement or disagreement with the speaker's arguments; words and phrases, having a colloquial connotation, phraseological units, proverbs, sayings, etc.) and correlating with specific goals, a specific contingent, its language level and desire to enter into communication.

A system of exercises corresponds to this task aimed at observing the use of speech structures in micro-situations, including problematic issues of future discussion-provocation and stimulating the production of a creative expression, which allows you to partially introduce the necessary vocabulary, test the competence of students in the designated range of questions, and also arouse interest to future communication.

The main stage is the actual discussion-provocation, where its exact topic is indicated, the subject of discussion is characterized, its main line is determined, various aspects of the problem are highlighted, the arguments of the author and the attitude of the participants in the discussion-provocation towards them are revealed.

For the practical implementation of what has been said, let's turn to the site materials 
https://www.molportal.ru/node/15743, where the journalist N. Zhukova is looking for an answer to the question "What is a student life?"

Life for me is ...

Elena Matyushina, undergraduate student of the Economics Faculty: "What does a student life mean to me, probably, I can say for sure only in a few years, when I graduate from the university. Now I will say one thing:

Student life is a constant movement.

First you watch a lot of TV shows, read fashion magazines, go with friends to clubs and cafes ... and at some point, you realize that the session is coming soon. So you sit at home all days and nights with books and coffee.

By the way, I'll tell you a funny story.

One day, after answering an exam, the teacher took my grade book to give it an "excellen". He looked at me and said:

- Well, and the last question: What is my name?

This was the only question I did not know the answer to".

Oksana Patseruk, 4th year student of the History Faculty: "A student life is the most interesting time. You get to know people, learn something new. And a student life for me is sleepless nights. But when I am asked about an interesting case, I immediately remember how I fell asleep at a lecture on History. When I woke up, the teacher asked if I had a good sleep. It was very funny".

Nikita Golubev, 3rd year student of the Engineering Faculty: "A student life for me is a new chapter in my life. It has a lot of pleasant moments: it is a favorite business, various events, competitions, new friends and, of course, excellent teachers. Last session, I knew what a real teacher humor is. After the session, I came to the dean's office to submit documents for the scholarship. The teacher to whom I passed the exam says:

- I am not sure that you know physics very well, you have to answer two more questions. Of course, I was shocked! I am taking a ticket and start remembering topics. After 30 minutes, I say I'm ready. I start to answer.

The teacher looks at me, smiles and says:

- It was a joke! Have a nice vacation!"

Violetta Kosmova, a first-year medical student: "A student life is a movement. You come to the university and think that all your thoughts will be only about studying, and then you start participating in almost all events. Because it is very interesting, because these are new acquaintances and new emotions! For example, I am very glad that I took part in the project "The Freshman's debut!" These are night rehearsals, friendly staff and a lot of positive emotions! And soon is "A Student's Spring". I'm looking forward to it!"

Andrey Ivanov, 4th year student of the Geology Faculty: "A student life is not only studies. Now it is the XXI century. There are lot of interesting entertainment and activities! So, I usually was preparing for the exam within 1-2 days. Did I pass the exams? Easy! Even if I had the most difficult ticket. The main thing is to speak beautifully and confidently! And speaking beautifully is a real art!"

Ksenia Kuznetsova, 2nd year student of the Faculty of Foreign Languages:

"When I entered the university, I realized that the university is a big world, and you are already a part of it. People from different countries, cities, villages, schools study here. Before university, I had never seen so many different people, so many opinions, characters! This is a real school of life! And time is often not enough. My first sleepless night was in my first year before my English exam. And such nights are repeated often".

At the preparatory stage, the teacher introduces vocabulary that, in his opinion, has not yet been mastered by this group of foreign students, and works it out in the appropriate exercises. Based on the proposed text, these can be lexemes and phrases such as "fall asleep, wake up, sleep well, oversleep, positive emotions, sleepless night, be in shock," and 
exercises to consolidate them are logical in nature.

For example: Restorer the first phrases.

1. - I'm in shock!

2. ? - I overslept.

3. - I had a sleepless night.

After the presentation of the article, it is advisable to identify how fully the recipients have understood its content. For this purpose, we can recommend a test focused on choosing the correct answer to a question or continuation of a phrase, as well as retelling. For example: Choose the correct answer.

\begin{tabular}{|c|l|l|}
\hline 1 & $\begin{array}{l}\text { 1 What didn't Elena Matyushina } \\
\text { know on the exam? }\end{array}$ & $\begin{array}{l}\text { a) what is the examiner's name } \\
\text { b) what exam does she take } \\
\text { c) answer to the ticket question }\end{array}$ \\
\hline 2 & $\begin{array}{l}\text { How long was Andrey Ivanov } \\
\text { preparing for the exam? }\end{array}$ & $\begin{array}{l}\text { a) a week } \\
\text { b) no more than two days } \\
\text { c) one night }\end{array}$ \\
\hline 3 & $\begin{array}{l}\text { Where do the students pass their } \\
\text { papers to receive the scholarship? }\end{array}$ & $\begin{array}{l}\text { a) to the department } \\
\text { b) to the rector's office } \\
\text { c) to the dean's office }\end{array}$ \\
\hline 4. & $\ldots$ & $\ldots$ \\
\hline
\end{tabular}

Choose the correct continuation of the offers.

\begin{tabular}{|c|l|l|}
\hline 1 & $\begin{array}{l}\text { "University is a real school of } \\
\text { life" - so says ... }\end{array}$ & $\begin{array}{l}\text { a) Ksenia Kuznetsova } \\
\text { b) Andrey Ivanov } \\
\text { c) Nikita Golubev }\end{array}$ \\
\hline 2 & $\begin{array}{l}\text { "A Student life is nights without } \\
\text { sleep" - so believes ... }\end{array}$ & $\begin{array}{l}\text { a) Oksana Patseruk } \\
\text { b) Andrey Ivanov } \\
\text { c) Nikita Golubev }\end{array}$ \\
\hline 3 & $\begin{array}{l}\text { "Speaking beautifully is a real } \\
\text { art" - so says ... }\end{array}$ & $\begin{array}{l}\text { a) Oksana Patseruk } \\
\text { b) Andrey Ivanov } \\
\text { c) Nikita Golubev }\end{array}$ \\
\hline 4. & $\ldots$ & ... \\
\hline
\end{tabular}

Tell us what the characters inf the text think about the student life.

After identifying the level of lexical and grammatical material mastering and the meaningful filling by foreigners, you can start directly to the discussion it-provocation. To do this, the teacher displays provocative phrases on the board and asks students to express their attitude towards them:

1) "On the exam, the main thing is not to know the answer to the question, but to speak beautifully and confidently";

2) "All students study a lot even at night, so student's life is always a night without sleep";

3) "Student's life means new acquaintances and new emotions";

4) "Student's life is the most difficult time in a person's life".

In the discussion process of the statements content, students either agree with it or object to it, arguing reasonably against certain provisions by proving their rightness [12]. As a homework assignment, you can ask foreigners to prepare a monologue on the topic "Student life for me is ..." [13].

\section{Conclusion}


All of the above allows us to conclude that properly organized educational communication in the classroom provides not only the creation of a favorable climate, but also makes it possible to improve the educational process, its individualization and pedagogical effectiveness in developing students' speech behavior skills, the ability independently to search for information, its rethinking and production of their own position [14]. The clash of different points of view during the discussion not only helps to deepen the students' knowledge and find the truth, but also shapes their worldview, promotes the cultivation of a culture of verbal communication, the ability to debate, to listen to the arguments of the opponent, reasonably express and defend your point of view on the issue under discussion. In this regard, discussion-provocation, being a non-standard form of classes, contributes to the formation of an abstract and scientific worldview among foreign students, actively develops their creative thinking, gives them the opportunity to express themselves as fully as possible [15], to develop the ability to master polemical dialogue, to combine thoughts expressing the sequence of phenomena and processes of reality, come to the awareness of their own individual existence in this world.

\section{References}

1. L. Stoll, Capacity for learning: Getting serious about practice improvement Leading Educational Change: global issues, challenges, and lessons on wholesystem reform. (New York, 2013)

2. H. Clark, Spoken discourse and its emergence. Cambridge handbook of psycholinguistics. Cambridge: Cambridge University Press, 541-557 (2012)

3. J. Gregersen-Hermans, How to design and assess an intercultural learning experience. Building cultural competence: innovative activities and models, 23-41 (2012)

4. T. S. Rodgers, Approaches and Methods in Language Teaching, 419 (Cambridge University Press, 2014)

5. M. Baker, Linguistics and the training of translators and interpreters. Meaning in translation. Frankfurt am Main, 427- 436 (2010)

6. C. Borghetti, How to teach it? Proposal for a methodological model of intercultural competence. Intercultural competence. Concepts, challenges, evaluations, Bern, 141159 (2011)

7. T. Harden, The perception of competence: a history of a peculiar development of concepts. Intercultural competence. Concepts, challenges, evaluations, 75-87 (Bern, 2011)

8. N. Coutts, Powerful Provocations for Learning: Sparking curiosity and increasing engagement. URL: https://thelearnersway.net/ideas/2019/8/11/powerful-provocationsfor-learning-sparking-curiosity-and-increasing-engagement (Last accessed 04.09.2020)

9. H. Clark, Unspoken questions, unspoken answers. Questions: Formal, functional and interactional perspectives, 81-102 (Cambridge, Cambridge University Press, 2012)

10. R. Chacyn-Beltron, Insights into Non-native Vocabulary Teaching and Learning, Multilingual Matters, 230 (2010)

11. A. Frampton, Provocation to Reflect: An Educator's Exploration of Engaging Students Through Documentation. Journal of Childhood Studies, 41(3) (2016)

12. T. Johnen, What can cross-cultural conversation transcript analysis contribute to the development of intercultural competence. Intercultural competence. Concepts, challenges, evaluations, 341-357 (Bern, 2011) 
13. M. Hebert, J. J. Bohaty, J. R. Nelson, J. V. Roehling, Reading and Writing, 31, 21652190 (2018)

14. O. V. Nikolenko, The author's "I" and its convincing function (on the example of a complex sentence with homogeneous adjuncts) 9th international scientific and practical conference "Actual issues of linguistics and didactics: an interdisciplinary approach in the Humanities” SHS Web of Conferences, (CILDIAH-2019), 69 (2019)

15. O. V. Nikolenko, Parcelled phrases in the aspect of business communication. IOP Conference Series: Materials Science and Engineering, 483 (2019) DOI: 10.1088 / $1757-899 \mathrm{X} / 483 / 1 / 012106$ 